\title{
1. A good FACT for climate change mitigation
}

\section{Cristina Brandimarte*}

\subsection{INTRODUCTION}

The global degree of carbon dioxide $\left(\mathrm{CO}_{2}\right)$ concentration in the atmosphere - a direct cause of global warming - has reached worrying record levels, and is continuing to rise along a steep upward trend. Global Carbon Budget (GCB) estimates ${ }^{1}$ point out that carbon concentration in the atmosphere increased by 85 parts per million (ppm) from 1959 to 2015, nearly 40 per cent of which was over the last 15 years, and that combustion of fossil fuels is the dominant and growing anthropogenic source of emissions.

GCB figures also point out that stabilizing or, even more, reducing $\mathrm{CO}_{2}$ concentration would require drastic global emissions abatement, considerably above 50 per cent. Such a great reduction, besides being difficult to attain within a reasonable time horizon, would entail huge costs for developing countries. Indeed, as International Energy Agency (IEA) figures show, ${ }^{2}$ non-OECD countries actually emit the greatest share of $\mathrm{CO}_{2}$, and the recent emissions' increase was driven by positive and desirable catching-up phenomena, with poorer countries experiencing mortality rate reductions and increases in well-being. Indeed, increases in global population and gross domestic product (GDP) per capita have been the main forces driving upward trends in $\mathrm{CO}_{2}$ emissions, while global emissions intensity has been progressively decreasing.

For these reasons, most recent guidelines ${ }^{3}$ suggest large-scale integrated approaches combining measures to both strengthen efforts to reduce emissions and boost carbon sequestration. Following these guidelines, a proper approach should be, for example, to price carbon and to use revenues to promote protection and development of carbon sink ecosystems. Hence, it becomes particularly important to adopt anti-emissions measures that do not harm the economy and free up resources to strengthen the climate change fight. 
Among market-based instruments, literature indicates that carbon taxes are one of the most cost-effective for emissions reduction. In particular, upstream (or production-based) $\mathrm{CO}_{2}$ taxation - a tax levied at the point where the source of emissions enters the economic system - is suggested as it has low administrative costs and ensures great coverage. If imposed unilaterally, however, this kind of tax could entail significant economic costs, mainly through competitiveness losses, and could become environmentally ineffective due to carbon leakage phenomena. Suggested co-measures, such as border tax adjustments or proper reuse of revenues, might not be sufficient to avoid these problems and to make a production-based carbon tax an easy win-win solution.

Literature then suggests as a viable alternative a different carbon tax design: namely the CAT (carbon-added tax), a downstream, or consumption-based, carbon tax modelled on value-added tax. It has the advantage of protecting competitiveness of domestic producers as it is levied on imports and reimbursed on exports.

In this chapter, the implementation of a fuel-added carbon tax (FACT) a duty levied on fossil fuel embodied in goods and services and patterned after VAT - is considered and compared with a tax on fossil fuel purchases (FCT), the simplest and most common upstream carbon tax. In particular, macroeconomic effects of both taxes are estimated for Italy, using MEMo-It, the macroeconometric model of the Italian National Institute of Statistics (ISTAT).

The remainder of the chapter is organized as follows. Section 1.2 briefly reviews characteristics and implications of production-based carbon taxes. Section 1.3 examines downstream taxation and describes the FACT. Section 1.4 deals with differences between FCT and FACT both from theoretical and empirical points of view. In particular, the effects of their implementation in Italy are analysed and compared. Some conclusions follow in section 1.5. A technical appendix on FACT simulation concludes the chapter.

\subsection{UPSTREAM TAXATION OF $\mathrm{CO}_{2}$ EMISSIONS: PRODUCTION-BASED CARBON TAXES}

Theoretical literature suggests imposing taxes directly on, or close to, environmental damage and proportional to the specific environmental cost. ${ }^{4}$ According to theory, a carbon tax on fossil fuel emissions should fall at different points of the production-consumption chain, where the fuel is burned, and should equal the marginal damage. Considering administrative costs, relative to measurement, management and control, 
it can, however, become optimal to impose the tax farther from the emissions and set it equal to the average damage. ${ }^{5}$ For these reasons, the most common carbon tax takes the form of a duty on fossil fuel purchases. It falls upstream, when fossil fuels enter the system, involves low administrative costs and is effective in the short and long run, inducing economic agents' behavioural changes and technological innovations that lead to structural emissions reduction. It should be noted that, even if imposed upstream, the price signal must reach consumers in order to fully achieve such desired effects. It is widely recognized ${ }^{6}$ that the major risk arising from the implementation of a unilateral production-based carbon tax, and the most important obstacle to its implementation, is the competitive disadvantage that can lead to shifting production abroad. This phenomenon, called carbon leakage, undermines the global emission reduction target, by reducing national emissions in the abating country but increasing emissions in non-abating ones, and poses a major challenge for designing effective unilateral policies aimed at mitigating global climate change. Finally, production-based carbon taxes have important, and inequitable, international burden-shifting implications.

\subsubsection{Carbon Leakage}

Carbon leakage may occur through several channels. First of all, the reduced demand for fossil fuels in the unilaterally abating country causes an international fuel price decrease, which means a demand increase and then an increase of emissions in countries with no or lower carbon pricing. The second channel works in the medium to long term and occurs because energy-intensive and trade-exposed industries in the unilaterally abating country lose competitiveness and their production is relocated to areas where abatement costs are lower. A further channel happens through substitution of domestic products with cheaper imported ones. Finally, the last channel, less considered in literature, affects the economy in the short to medium term and becomes important if the exchange rate is not fully flexible and costs are indexed. It is due to the 'cascading effect' on costs that occurs through both wages indexation and increases in prices of domestically produced inputs. This results in further competitiveness losses and therefore in additional incentives to move production abroad. If entrepreneurs anticipate this development, a stronger carbon leakage effect should happen in the short term.

Theoretical and empirical literature widely agree that economic costs from a unilateral carbon tax the main obstacle to environmental taxes implementation. To overcome these limits, several anti-leakage measures 
have been proposed: border tax adjustment, industry exemption, subsidies and rebates, and reuse of revenues to reduce other more distortive taxes ('double dividend' literature). ${ }^{7}$ Anti-leakage proposed measures are, however, second-best instruments that could lead to reduced environmental benefits, provide little or no incentive to cut emissions, and result in protection of sectors with greater emission intensity with respect to the rest of the world. ${ }^{8}$

Among instruments aiming to reduce carbon leakage without reducing environmental benefits of a unilateral carbon tax, border tax adjustments (BTAs) are widely regarded as the most effective instruments. They are aimed at levelling the playing field between the national regulated industries and unregulated industries abroad, usually taxing imports to the same extent as domestically produced goods and exempting exports. This solution has, however, some important limits. First of all, a correct implementation of BTAs could be excessively complicated and could have extremely high administrative costs. ${ }^{9}$ Second, BTAs do not avoid increased prices of domestically produced inputs and the ensuing negative effects on competitiveness. Finally, compliance of BTAs with World Trade Organization (WTO) rules is highly controversial, as such border adjustments might be considered a barrier to international trade, by discriminating against some imports in favour of domestic products or other imports, or by restricting trade between developed and developing countries.

\subsubsection{International Burden-shifting Implications}

In a context where about one-quarter of the carbon released is associated with production of internationally traded goods and services, ${ }^{10}$ the upstream carbon tax has important implications for international burden distribution. The tax burden, indeed, will weigh differently on countries, according to their production characteristics and their position along the so-called carbon supply chain. ${ }^{11}$ Carbon supply chains follow goods' flows according to their embodied carbon, that is, $\mathrm{CO}_{2}$ emissions that are needed to produce them, from extraction or production of raw materials and intermediate goods, up to final consumption, including transport activities. This approach enables consideration of 'the geographic separation of consumers and the pollution emitted in the production of the consumable items' 12 and shows that within a single country there could be significant differences between 'produced emissions' and 'consumed emissions'.

Countries can indeed be distinguished into three main groups: at one end, countries that are net exporters of fossil fuels; in the middle, countries 

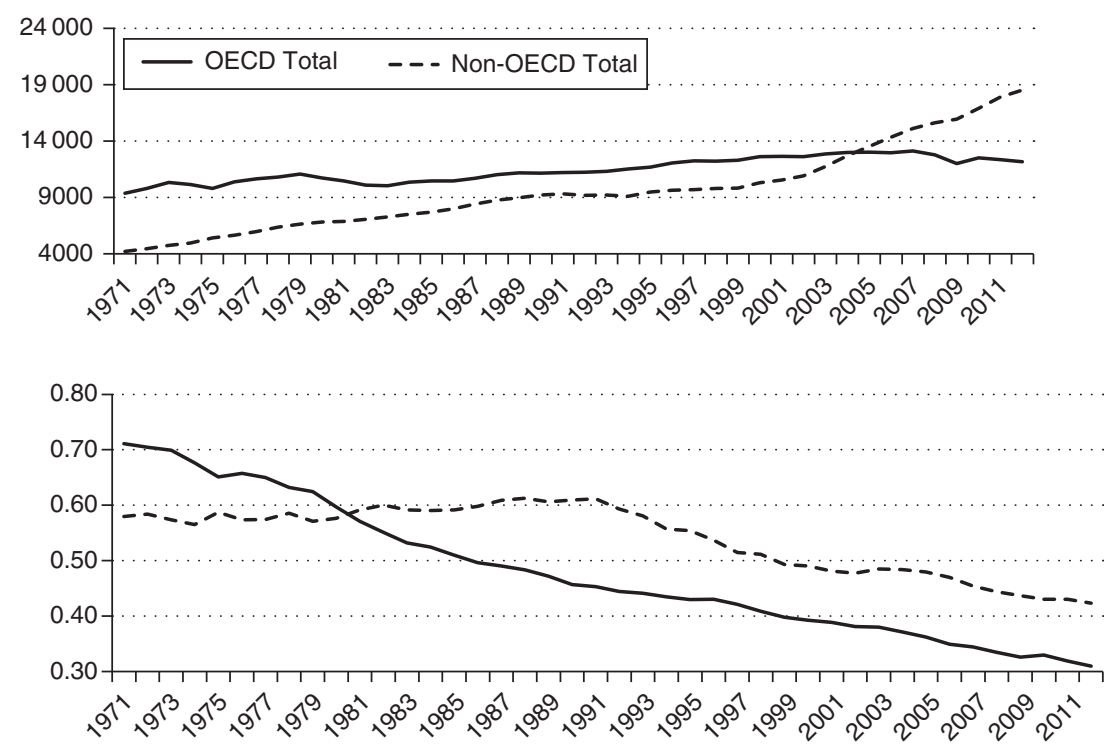

Source: $\quad \mathrm{CO}_{2}$ Emissions from Fuel Combustion (2014 edition), Paris: IEA.

Figure 1.1 $\mathrm{CO}_{2}$ emissions from fossil fuels (a) million tonnes of $\mathrm{CO}_{2}$ and (b) in percentage of GDP (using purchasing power parities $\mathrm{Kg} \mathrm{CO}_{2} / U S \$$, 2005 prices)

that are net exporters of embodied carbon (manufacturing countries); and countries that are net importers of embodied carbon (consumer countries) at the other end of the chain. Countries located at both ends of the international supply chain evade environmental responsibility by shifting emissions associated with their consumption to countries in the middle of the chain. ${ }^{13}$ Since the beginning of the century, most $\mathrm{CO}_{2}$ from fuel combustion has been emitted by developing countries (located in the middle of the chain), while the share of emissions by developed countries has significantly declined, as shown in Figure 1.1.14

Implementation of a production-based carbon tax would fall heavily on poorer countries, disproportionately compared to national consumption choices, with severe implications in terms of global equity. ${ }^{15}$ Furthermore, the implementation of production-based carbon taxes in countries at the end of the chain has little environmental effectiveness. 


\subsection{DOWNSTREAM TAXATION: CONSUMPTION- BASED CARBON TAXES}

An alternative measure to production-based carbon taxes suggested by the literature is downstream taxation, that is, a tax imposed on final consumption. ${ }^{16}$ A consumption-based carbon tax is imposed on carbon embodied in final goods and services and shifts the responsibility from territorial to consumption emissions. Pricing carbon downstream has the advantage of protecting competitiveness of domestic producers and can be more easily implemented. Furthermore, other countries are stimulated to price carbon to retain border tax revenues. ${ }^{17}$ Literature suggests the carbon-added tax (CAT), that is, a tax based on carbon embodied in products and modelled on VAT.

The major criticisms of consumption-based carbon taxes are the possible conflict with international trade law and an extremely complicated implementation, as with BTAs. ${ }^{18}$ However, a growing body of legal experts agree on compliance of well-designed consumption-based approaches with WTO rules and it can be argued that, as in the case of upstream taxation, second-best solutions can be found to facilitate its implementation and minimize administrative costs. For example, a consumption-based tax on fossil fuels could be much simpler to manage with respect to taxes on carbon content and can be a viable alternative to common taxes on fuel purchases.

\subsubsection{Fuel-added Carbon Tax}

A fuel-added carbon tax (FACT) is a duty levied on the fuel that is added at each stage. Like VAT, the product is taxed at the end of each stage on its cumulative fuel content to that point, and credit is allowed for tax paid on fuel embodied in purchased inputs and refunded if net liability is negative. At the final stage, the tax is on the cumulative fuel used and is equivalent to the sum of the fuel-added carbon taxes at each stage.

In the case of exports, the tax accumulated will be rebated, so that the tax does not impact international competitiveness. At the same time, a fuel tax will be levied on the imported products. Ideally, this tax should be based on imports' real fuel content but, where it is not known, imports will be taxed to the same extent as homogeneous products that are domestically produced by the predominant production method.

FACT is similar to a duty on fuel purchases with border tax adjustments. Both of them aim to level the playing field between domestic and foreign firms, trying to convert origin-based fuel prices to consumptionbased prices and limiting competitive disadvantages for the imposing 
country. But important differences lie between the two. First of all, FACT is imposed not only on fuel goods but also on non-fuel goods, according to their fuel content. In other words, it is levied on all goods that are domestically consumed, wherever they are produced. ${ }^{19}$ Second, the FACT burden falls directly and entirely on domestic final consumers and does not affect prices of intermediate products, limiting negative effects on competitiveness. Further, FACT reduces incentives for tax evasion and provides incentives for exporting countries to adopt their own carbon prices, especially if it involves the refunding of $\mathrm{CO}_{2}$ taxes already paid abroad on imported goods.

Last but not least, there are stronger arguments in favour of FACT's compliance with WTO rules, as it can be considered as a VAT with flexible rates, where rates vary in order to reflect fossil fuel content following production improvements and technological progress.

\subsection{UPSTREAM VS DOWNSTREAM FUEL TAXATION}

Major differences between the FACT and the FCT are related to tax bases and price effects. We may analyse these differences starting from the following equation, expressing a country's fossil fuels budget:

$$
F C=F E+F M-F X
$$

where:

$F C=$ total final fuel consumption;

$F E=$ total fuel domestic extraction;

$F M=$ total fuel imports;

$F X=$ total fuel exports.

Each addendum in expression (1.1) is referred to the total fuel and may be disaggregated into fuel and non-fuel products as follows:

$$
F C f+F C n f=F E+F M f+F M n f-F X f-F X n f
$$

where:

$F C f=$ fuel final (direct) consumption;

$F C n f$ = final consumption of fuel embodied in non-fuel products;

$F M f=$ imported fuel;

$F M n f=$ fuel embodied in non-fuel imported goods and services;

$F X f=$ exported fuel;

$F X n f=$ fuel embodied in non-fuel exported goods and services. 
Table 1.1 Effects on prices of FCT and FACT

\begin{tabular}{|c|c|c|c|c|c|}
\hline & \multirow[t]{2}{*}{ Production Prices } & \multirow[t]{2}{*}{ Consumer Prices } & \multicolumn{2}{|c|}{ Import Prices } & \multirow[t]{2}{*}{ Export Prices } \\
\hline & & & FMf & FMnf & \\
\hline FCT & $\mathrm{X}$ & $\mathrm{X}$ & $\mathrm{X}$ & - & $\mathrm{X}$ \\
\hline FACT & - & $\mathrm{XX}$ & $\mathrm{X}$ & $\mathrm{X}$ & - \\
\hline
\end{tabular}

Note: Dashes signal no effect. $\mathrm{XX}$ indicates a much stronger effect than $\mathrm{X}$.

Tax bases can be then expressed as follows:

$$
\text { FCT's tax base }=F E+F M f-F X f
$$

FACT's tax base $=F E+F M f+\boldsymbol{F M n f}-F X f-\boldsymbol{F X} \boldsymbol{n} \boldsymbol{f}$

The tax base's difference (bold addenda) depends on the trade balance of fuel embodied in non-fuels products. As developing countries, located in the middle of the carbon supply chain, have a negative balance, in those countries FCT's tax base is larger than FACT's tax base. The opposite happens in developed countries.

With regard to short-term impacts on prices, these are shown in Table 1.1.

FCT affects the firm's purchase price of fuel and then has the effect of increasing production prices and export prices. Consumption prices are affected directly by the tax levied on final consumption of fossil fuels and indirectly through the translation of production price increases.

FACT has no effect on production prices or on export prices. Consumer prices are directly affected through two channels: the tax levied on final consumption of fossil fuels and the tax levied on fuel embodied in non-fuel products consumed by final consumers.

\subsubsection{Empirical Evaluation for Italy}

In this section empirical evaluations for Italy are presented. Macroeconomic effects of both FCT and FACT have been simulated over a four-year time horizon using the ISTAT (Italian National Institute of Statistics) macroeconometric model (MEMo-It). ${ }^{20,21}$

Fiscal measures amount to 1 percentage point of GDP in the ex ante evaluation ${ }^{22}$ for FCT and tax rates are set equal in the two simulations. The ex post macroeconomic effects ${ }^{23}$ are evaluated with respect to a baseline scenario based on the May 2014 ISTAT official forecast. 
Simulation exercises are based on the following hypotheses:

- The country is small and belongs to a single monetary area. That means that nominal interest rates and nominal exchange rates remain unchanged with respect to baseline.

- Wages are indexed to consumer prices.

- Income taxation is progressive but income brackets are indexed, so that a fiscal drag does not occur.

- Entrepreneurs do not expect significantly restrictive effects on domestic demand or on competitive position and react to the lower real interest rates and the introduction of fuel tax, increasing investments.

- Fuel intensity of goods and services is assumed to be the same, on average, for imported, exported and domestically produced goods.

Results are shown in Table 1.2.

In the first exercise the introduction of the FCT (duty on fossil fuel purchases) is simulated. ${ }^{24}$ Results indicate that two periods can be distinguished: the first two years are characterized by a slightly positive effect while in the following two years a depressive effect on the economy occurs. In the first period, restrictive effects come from the reduction of households' real disposable income and are offset by expansive effects coming from terms of trade gains ${ }^{25}$ and from the real interest rate reduction. Moreover, negative effects on exports are limited by low (estimated) elasticities of both the export deflator to changes in fuel prices and foreign demand of Italian products to export deflator. In the second period, the effects of higher inflation on production costs, in particular on indexed labour costs, result in a significant loss of competitiveness, which is mainly reflected in an increase in imports, since consumption of domestic goods is reduced in favour of cheaper imported ones.

In the second exercise the introduction of a FACT is simulated. Some relevant differences with respect to FCT simulation are evident. In the first period, inflation is higher and reduction of households' real disposable income is stronger, but they are associated with a stronger reduction in imports, as the tax is levied not only on fuels, as in the case of FCT, but also on non-fuel imported goods. Exports remain unchanged, as in the FCT simulation. As a result, expansive effects on GDP are stronger. In the second period, exports are not hit and imports continue to shrink. No carbon leakage effect occurs and investment and GDP growth are still positive. Higher real economic growth and higher inflation exert positive effects on public budget balance and on households' disposable income. 
Table 1.2 Simulation results for FCT and FACT effects in Italy (differences from baseline)

\begin{tabular}{|c|c|c|c|c|c|c|c|c|}
\hline & \multicolumn{5}{|c|}{ Tax on Fuel Purchases (FCT) } & \multicolumn{3}{|c|}{$\begin{array}{c}\text { Fuel-added Carbon } \\
\text { Tax (FACT) }\end{array}$} \\
\hline & 2015 & 2016 & 2017 & 2018 & 2015 & 2016 & 2017 & 2018 \\
\hline GDP & 0.1 & 0.0 & -0.2 & -0.2 & 0.2 & 0.1 & 0.1 & 0.0 \\
\hline $\begin{array}{l}\text { Domestic } \\
\text { demand }\end{array}$ & -0.1 & -0.2 & -0.1 & -0.1 & -0.2 & -0.3 & -0.1 & 0.0 \\
\hline $\begin{array}{l}\text { Household } \\
\text { consumption }\end{array}$ & -0.1 & -0.4 & -0.1 & 0.0 & -0.2 & -0.5 & -0.1 & 0.0 \\
\hline Investments & 0.1 & 0.2 & -0.3 & -0.4 & 0.2 & 0.5 & 0.2 & -0.1 \\
\hline Exports & 0.0 & 0.0 & -0.2 & -0.2 & 0.0 & 0.0 & 0.0 & -0.1 \\
\hline Imports & -1.1 & -1.1 & 0.2 & 0.4 & -1.2 & -1.5 & -0.5 & -0.3 \\
\hline GDP deflator & 0.7 & 0.6 & 0.5 & 0.3 & 1.0 & 0.8 & 0.6 & 0.5 \\
\hline $\begin{array}{r}\text { Consumer } \\
\text { deflator }\end{array}$ & 1.0 & 0.6 & 0.3 & 0.2 & 1.4 & 0.8 & 0.5 & 0.3 \\
\hline $\begin{array}{l}\text { Export } \\
\text { deflator }\end{array}$ & 0.0 & 0.0 & 0.3 & 0.3 & 0.0 & 0.0 & 0.0 & 0.4 \\
\hline Employment & 0.3 & 0.1 & 0.0 & -0.1 & 0.4 & 0.2 & 0.0 & 0.0 \\
\hline Fuel tax/GDP & 0.6 & 0.4 & 0.3 & 0.2 & 0.5 & 0.3 & 0.2 & 0.1 \\
\hline $\begin{array}{l}\text { Net lending/ } \\
\text { GDP }\end{array}$ & 0.7 & 0.7 & 0.6 & 0.5 & 0.7 & 0.8 & 0.7 & 0.7 \\
\hline $\begin{array}{l}\text { Gross debt/ } \\
\text { GDP }\end{array}$ & -1.8 & -3.2 & -4.1 & -4.7 & -2.2 & -4.0 & -5.4 & -6.8 \\
\hline $\begin{array}{l}\text { Real } \\
\text { disposable } \\
\text { income ( } \% \\
\text { change) }\end{array}$ & -0.8 & -0.1 & 0.1 & 0.0 & -1.1 & -0.1 & 0.1 & 0.1 \\
\hline $\begin{array}{l}\text { Real } \\
\text { disposable } \\
\text { income }(\% \\
\text { difference } \\
\text { with respect } \\
\text { to baseline) }\end{array}$ & -0.8 & -0.9 & -0.8 & -0.8 & -1.1 & -1.2 & -1.1 & -1.0 \\
\hline
\end{tabular}

\subsection{CONCLUSIONS}

Empirical results indicate that in Italy, a small country belonging to a monetary area that is a net importer of fossil fuels, the implementation of a FACT should be more effective and less costly with respect to a tax on fuel purchases. 
Without competiveness losses, benefits coming from terms of trade gains and the stimulus to invest in new, fuel-saving technologies can be fully exploited, with positive effects on both the economy and the environment. Public finance conditions improve too, and resources then become available to strengthen efforts to reduce $\mathrm{CO}_{2}$ atmospheric concentration, for example enhancing carbon sink ecosystems. A further simulation, not shown here, indicates that recycling revenues to promote sustainable development, for example, boosting forest management and linked economic activities, should help to reach multiple environmental and socioeconomic targets without worsening public finance.

\section{NOTES}

* The views expressed in this study are those of the author and do not represent those of the Italian National Institute of Statistics (ISTAT), with whom she is affiliated.

1. Global Carbon Budget Archive (2014), accessed 5 April 2016 at http://www.globalcarbonproject.org/carbonbudget/archive.htm\#CB2014.

2. IEA (2014), $\mathrm{CO}_{2}$ Emissions from Fuel Combustion Highlights 2014, accessed 5 April 2016 at http://www.iea.org/publications/.

3. Intergovernmental Panel on Climate Change (2014), Fifth Assessment Report: Climate Change 2014, accessed 5 April 2016 at http://www.ipcc.ch/report/ar5/wg2/.

4. Pigou, A.C. (1920), Economics of Welfare, London: Macmillan; Heine, D., J. Norregaard and I.W.H. Parry (2012), 'Environmental tax reform: principles from theory and practice to date', IMF Working Paper WP/12/180.

5. Baumol, W.J, and W.E. Oates (1971), 'The use of standards and prices for the protection of the environment', Scandinavian Journal of Economics, 73(1), 42-54; Pearce, D.W. (1991), 'The role of carbon taxes in adjusting to global warming', Economic Journal, 101(407), 938-48.

6. Intergovernmental Panel on Climate Change (2008), Fourth Assessment Report: Climate Change 2007, accessed 5 April 2016 at https://www.ipcc.ch/pdf/assessment-report/ ar4/wg2/ar4_wg2_full_report.pdf; OECD (2014), Competitiveness Impacts of Carbon Pricing: A Review of Empirical Findings COM/ENVICTPA/CFA(2014) 20.

7. A large body of literature has analysed the possibility of getting a double dividend by recycling carbon tax revenues, but the issue is still largely debated and no certain and agreed conclusions have been reached.

8. Literature shows that environmental effectiveness of anti-leakage measures heavily depends on differences between abating and non-abating countries.

9. Pauwelyn J. (2012), 'Carbon leakage measures and border tax adjustments under WTO law', working paper, accessed 5 April 2016 at http://papers.ssrn.com/sol3/papers. cfm?abstract_id=2026879.

10. Peters, G.P., S.J. Davis and R. Andrew (2012), 'A synthesis of carbon in international trade', Biogeosciences, 9, 3247-76.

11. Davis, S.J and K. Caldeira (2010), 'Consumption-based accounting of $\mathrm{CO}_{2}$ emissions', in Proceedings of the National Academy of Sciences of the United States of America, 107(12), 5687-92; Harrison, K. (2015), 'International carbon trade and domestic climate politics', working paper, accessed 5 April 2016 at http://depts.washington.edu/ envirpol/wp-content/uploads/2015/02/Colloquia_Harrison.pdf.

12. Peters, G.P and E.G. Hertwich (2008), ' $\mathrm{CO}_{2}$ embodied in international trade with implications for global climate policy', Environmental Science and Technology, 42(5), 1401-7.

13. Many fossil fuel exporters have clean economies and are net importers of carbon 
embodied in non-fuel products. See Harrison, K. (2015) 'International carbon trade and domestic climate politics', working paper; at http://depts.washington.edu/envirpol/ wp-content/uploads/2015/02/Colloquia_Harrison.pdf.

14. Davis, S.J., G.P. Peters and K. Caldeira (2011) 'The supply chain of $\mathrm{CO}_{2}$ emissions', in Proceedings of the National Academy of Sciences of the United States of America, 108(45), 18554-9.

15. Economic activity in manufacturing countries could be very strongly damaged by imposing an unilateral, production-based, carbon tax: the competitiveness loss would suddenly lead to a drop in demand of domestically produced goods, to carbon leakage phenomena and to a strong reduction of economic activity and fiscal revenues. A global uniform carbon tax, on the other hand, would suddenly delete the competitive advantage that has driven poorer countries' economic growth, with negative consequences that could hardly be eliminated without an international redistribution of carbon tax revenues.

16. Christian, A.C. (1992), 'Designing a carbon tax: the introduction of the carbonburned tax', UCLA Journal of Environmental Law and Policy, 10(2), 221; Duff, D.G. and M. MacDonald (2013), 'Towards a destination-based carbon tax', Proceedings of the 14th Global Conference on Environmental Taxation, Kyoto, Japan, 17-19 October; Harrison, 'International carbon trade and domestic climate politics'.

17. Harris, P. and J. Symons (2013), 'Norm conflict in climate governance: greenhouse gas accounting and the problem of consumption', Global Environmental Politics, 13(1), $9-29$.

18. For a detailed critique, see McLure, C.E.Jr(2010), 'The carbon-added tax: a CAT that won't hunt', Policy Options Politiques, 1 October, accessed 6 April 2016 at http://policyoptions. irpp.org/magazines/obama-at-midterm/the-carbon-added-tax-a-cat-that-wont-hunt/.

19. Tax rates being equal, FACT leads to higher inflation.

20. For a synthetic description of the model and its transmission channels see Brandimarte, C. (2014), 'Macroeconomic effects of environmental tax subsidy reform: an evaluation for Italy', in L. Kreiser et al. (eds), Environmental Taxation and Green Fiscal Reform -Theory and Impact, Critical Issues in Environmental Taxation Volume XIV. For a detailed description see Bacchini, F. et al. (2013), 'Building the core of the ISTAT system of models for forecasting the Italian economy: MEMo-It', ISTAT Rivista di Statistica Ufficiale, 2013(1), 17-26.

21. The methodology used to simulate the fuel-added carbon tax is explained in the Appendix to this chapter.

22. Ex ante evaluation means that economic agents do not change their behaviour in response to the introduction of the tax.

23. Ex post macroeconomic effects account for direct and indirect effects.

24. For a similar exercise see Brandimarte, 'Macroeconomic effects of environmental tax subsidy reform: an evaluation for Italy'. The main difference with respect to that simulation lies in a more optimistic reaction of private investments.

25. Imports decrease more than GDP and internal demand, since consumption of fuel, largely imported, decreases, and consumption of national products increases. 


\section{APPENDIX}

In this Appendix the methodology used to simulate fuel-added carbon tax (FACT) with the ISTAT macroeconometric model is explained. The approach followed is to consider differences from the tax on fuel purchases (FCT), already modelled in MEMo-It, and to accordingly amend the relevant equations. FACT differs from FCT in two respects: effects on consumer prices and effects on revenues.

Effects on prices Differential effects on prices are modelled considering the FACT's additional effect on consumer deflator growth with respect to FCT and to baseline. This additional effect reflects the tax on fuel embodied in non-fuel goods. ${ }^{1}$ It is calculated assuming that fuel intensity is the same, on average, for imported, exported and domestically produced goods.

Effects on revenues To estimate revenues from FACT, we face the problem of calculating the tax base. FACT's tax base differs from FCT's tax base by the balance between fuel embodied in non-fuel exported and imported goods. These variables are expressed in the model in nominal and real terms, but not in quantity (barrels) of fuel content, as required to estimate revenues. We need a conversion factor to transform variables expressed in real terms to variables expressed in barrels of embodied fuel, the same unit as the FCT's tax base.

This conversion factor (gamma) is estimated by combining the following two different ways to calculate FACT's revenues: in differential terms with respect to FCT revenues; multiplying the tax rate times total fuel final consumption expressed in barrels. Formally:

$$
\begin{gathered}
\mathrm{FACT}=\mathrm{FCT}-\mathrm{t} * \mathrm{I} *(\mathrm{X}-\mathrm{Mnf}) \\
F A C T=t * C F f * \text { gamma }+t * I * C F n f
\end{gathered}
$$

where:

FACT indicates revenues from the fuel-added tax;

$F C T$ indicates revenues from the tax on fuel purchases, where $F C T=t *$ FUEL and FUEL indicates total fuel goods (barrels) that are domestically purchased, both by firms and final consumers;

$t$ is the tax rate (applied to fuel barrels);

$I$ indicates fuel intensity of goods: it is assumed to be the same, on average, for imported, exported and domestically produced goods and services;

$X$ indicates total exports (volume);

$M n f$ indicates imports of non-fuel goods; 
$C F f$ is the final fuel consumption (volume) and $\left(I^{*} C F n f\right)$ is the fuel embodied in final consumption of non-fuel goods expressed in barrels. ${ }^{2}$

Once gamma is calculated, FACT's revenues are easily estimated with equation (A1.1).

How to calculate conversion factor gamma As stated above, gamma is calculated by combining equations (A1.1) and (A1.2):

$$
\text { gamma } \left.=\left(F U E L-I^{*}(X-M n f)-I^{*} C F n f\right) / C F f\right)
$$

where the numerator represents the number of barrels embodied in final fuel goods ${ }^{3}$ and denominator the same quantity expressed in volume $(C F f)$. As numerator and denominator represent the same quantity expressed in the two different units, gamma is the number of barrels per volume unit (conversion factor).

How to calculate fuel intensity (I) I represents the fuel embodied in goods and services and it is assumed to be the same (on average) for domestically produced, consumed, exported and imported goods. $I$ expresses the number of barrels used by firms to produce a unit of goods and services (volumes):

$$
I=(q * F U E L) /\left(Y-k^{*} C\right)
$$

where:

$q$ is the share of fuel barrels used by firms and it is obtained residually, after estimating the share of fuel that is directly consumed;

$Y$ is total product (in volume);

$C$ is total consumption (in volume);

$k$ is the ratio between direct fuel consumption of households and total household consumption (as in national accounts). ${ }^{4}$

\section{Notes}

1. Mainly imported non-fuel goods.

2. CFf times gamma is final fuel consumption expressed in barrels.

3. Indeed: $F U E L=$ purchased fuel (barrels); $I^{*} X=$ total exported fuel (directly or embodied in exported goods and services), expressed in barrels (if $I$ is expressed in barrels too); $I^{*}(M n f)=$ fuel barrels embodied in imported non-fuel goods; $I * C F n f=$ fuel barrels embodied in final consumption of non-fuel goods.

4. These simplifying assumptions are not very restrictive as, even with changing of shares between direct and indirect consumption of fuel by household, revenues would not change significantly. A further assumption is that the proportion between firms' and households' consumption of fuel (direct or embodied) does not vary. In other words, if tax rates increase, fuel consumption decreases in the same proportion everywhere (direct consumption of households, manufacturing activities, exported products). 